\title{
Internet-based Carrying-out Strategy of Personalized Supplementary Education: A Case Study of School-based Practice in Middle School A in Jiangsu, China
}

\author{
Xuyue Xia, ${ }^{1}$ Lerongrong Chang, ${ }^{2}$ Fangmei $\mathrm{Li}^{3}$ \\ 1. Nantong University, Nantong, China \\ 2. East China Normal University, Shanghai, China \\ 3. China Tao Xingzhi Research Association Wisdom Education \\ Research Institute, Nanjing, China
}

\begin{abstract}
As an integral part of classroom teaching, after-school tutoring has always been valued by teachers and parents. Although outside school tutoring classes have largely filled the vacancy of after-school learning, their effectiveness cannot be guaranteed and the cost is high. Therefore, after-school supplementary learning based on the Internet has become a new choice for parents and teachers. How to use the network system to achieve the integration of inside and outside the school, inside and outside the classroom, how to use the network to assist students to meet the needs of students' differentiated and personalized learning is the key content that needs to be resolved in the construction of "Internet+" personalized after-school assistance. This article will take the school-based practice of a middle school in Jiangsu Province, China as an example, and explore the implementation strategy of personalized supplementary learning with the Internet as a carrier.
\end{abstract}

Sci Insigt Edu Front 2019; 4(2):419-433.

Doi: 10.15354/sief.19.ar265.

Keywords: Middle School; Internet+; After-School Supplementary Learning; Personalization; Implementation Strategy

Correspondence to: Lerongrong Chang, Postgraduate, Department of Education, East China Normal University, Shanghai, China, Email: $525780831 @ q q . c o m$. 

"shadow education" by researchers because its curriculum is similar to that of public school. In recent years, shadow education has developed rapidly worldwide. Developed countries and developing countries can see various forms of shadow education everywhere (Bray, 1999). Accordingly, in India, France, Malta, and Romania, more than one-third of students often receive extracurricular educational (Bailey, 2007). In China, shadow education has become a common phenomenon. No matter where they are, in cities or towns, most families of elementary and middle school students will choose to use extracurricular time to participate in coaching training to improve their performance. The family's attention to extracurricular tutoring has gradually increased the proportion of family education proportion, and students' academic competitions outside the classroom have become increasingly fierce. In contrast, this extracurricular tutoring system is not perfect; there are problems such as low entry thresholds, difficult to guarantee teaching quality, too many part-time tutors, and overburdened parental expenses, etc. With the development of the internet, the use of the internet for out-ofschool supplementary education has become a new choice for school teachers and parents. Middle School A in Jiangsu Province, China uses the Internet to build a schoolbased supplementary learning platform, which allows students to obtain timely, free, and targeted after-school supplementary studies while acquiring much richer learning resources, making both academic performance and comprehensive quality get promoted. We herein will use the school-based practice of the Middle School A as an example to discuss its implementation strategy of personalized supplementary learning after class.

\section{Background}

As a supplement to regular classroom teaching, after-school tutoring can make up for the lack of students' knowledge in the classroom caused by the limited class-teaching time. It is of great significance for students to eliminate differences in classroom learning and improve performance. Therefore, extracurricular supplementary learning is considered to be "a powerful way to achieve a balanced distribution of educational resources through the sharing of teachers and physical facilities, etc., which can effectively solve the problem of uneven distribution of educational resources" (Fan, 2003; Wu, 2013). It is critical to achieve educational equity and promote educational development (Chen, 2019).

The Survey Report on the Status Quo of Teachers in China's Tutoring Education Industry and Tutoring Institutions issued by the China Education Society shows

\footnotetext{
About the Author: Xuyue Xia, Postgraduate, School of Educational Science, Nantong University, Nantong, Jiangsu, China, Email: 616636896@qq.com.

Fangmei Li, China Tao Xingzhi Research Association Wisdom Education Research Institute, Nanjing, Jiangsu, China,Email:1037576462@qq.com.
}

Conflict of Interests: None. 
that the market size of tutoring agencies in China's primary and secondary schools exceeded 800 billion in 2016, the number of students participating in extra-curricular tutoring exceeded 137 million, and the number of teachers in tutoring institutions reached 700- 8.5 million (Xinhua News Agency, 2016).

In terms of tuition fees, the cost of extra tuition has become an important part of family education expenditure. Based on the data of four follow-up surveys of the Chinese Family, 2010, 2012, 2014, and 2016 conducted by the Chinese Social Science Survey Center of Peking University, the total expenditure of extracurricular tutoring for compulsory education students in China was 48.099 billion CNY, 79.221 billion CNY, 108.377 billion CNY, and 51.697 billion CNY, respectively, and that account for about $0.12 \%, 0.15 \%, 0.17 \%$ and $0.17 \%$, and $0.07 \%$ of the GDP of the year, respectively. So, it is concluded that "China's compulsory education students participate in a large number of extra-curricular tutoring and pay higher tuition fees for this purpose." (Xue \& Fang, 2019).

Meanwhile, due to the complexity of the social tutoring market, scholars have questioned the effectiveness of tutoring. They believe that extracurricular tutoring does not have the qualified teachers in some tutoring institutions. The teaching content and design are not related to the students' physical and mental development level. Therefore, it was concluded that extracurricular tutoring is not effective for improving the overall quality of education (Ma, 2010).

In the context of the nation's advocacy of "burden reduction and efficiency enhancement" education and teaching, how to properly and effectively provide extracurricular tutoring is a question that every teacher needs to think about. The emergence and development of the internet provides the possibility to solve this problem. Taking the network platform as a carrier, teachers establish high-quality online teaching resources and present them to students in a certain way for students to browse, study and discuss. And use the Internet resources to push personalized learning materials for students, so as to effectively solve students' doubts and difficulties in the learning process, mobilize students' enthusiasm for learning, and cultivate good learning methods and habits.

Middle School A uses the existing home-school platform and deeply explores the personalized functions of the platform to provide after-school online supplementary courses. Use the Internet to achieve after-school communication and interaction between teachers and students, accurately push personalized learning resources according to the learning situation of students, customize personalized learning plans, and carry out personalized supplementary learning after class. This meets the needs of students' differentiated and personalized learning, and promotes the overall improvement of students' academic level and comprehensive literacy.

\section{Constructive Goals and Contents}

\section{Constructive Goals}


The school meets the needs of students 'individualized learning and develops students' autonomous learning capabilities as the goal, and develops an online auxiliary learning platform after class. Use excellent teachers to set up online after-school supplementary courses and carry out personalized after-school supplementary studies. The purpose is to provide students with free after-school online learning tutoring through the "Internet +" after-school personalized supplementary study under the guidance of the "education suitable for each child" concept. By allowing students with different learning needs to enjoy more suitable resources and guidance, to meet the needs of students' differentiated and personalized learning, focus on the evaluation of students' quality, and promote the overall improvement of students' academic level and comprehensive literacy. And strive to achieve "fair and quality compulsory education" for every child.

\section{Construction Contents}

Use the internet for personalized supplementary learning to meet the needs of students' differentiated and personalized learning after class, and to achieve free, synchronous and accurate learning guidance, learning remedy and literacy improvement.

\section{Construction of an After-School Supplementary Learning Platform Based on Student Learning Levels}

The construction of the auxiliary education platform is the technical support for the personalized auxiliary education after class. It requires more than just a presentation as a tool, but can integrate "information technology with the curriculum ... emphasizing the use of information technology to create A new type of teaching environment that can support the teaching methods and learning methods required for the creation of realistic situations, inspiring thinking, information acquisition, resource sharing, multiple interactions, autonomous inquiry, collaborative learning, etc." (He, 2005).

\section{Make Up for Student Learning Differentiation and Meet Individual Learning Needs}

Personalized supplementary education needs to meet the goal of students' individualized learning differences, and to resolve the contradiction between the difference in the degree of learning within the school's time limit and the level of learning required by the curriculum. The traditional after-school supplementary study does not take into account the uneven learning levels of students, and uniformly arranges exercises, which makes "the students who have mastered iterate repeatedly, do more labor, and the improvement is not that obvious."(Wan, 2016). Personalized supplementary education requires the support of personalized services, which requires prior knowledge of the student's learning situation so as to provide hierarchical counseling. 


\section{Resource Support for Students' After-School Supplementary Learning under the Standard School Behavior}

Curriculum resources are the core competitiveness of online teaching. "Online teaching can neither be" full-filled "like traditional education, nor can digital resources be put on the server to allow students to learn autonomously." (Wen et al, 2017). After-school supplementary education should be well integrated within and outside the school, integrates the excellent resources of the school, and actively develop personalized supplementary educational resources that meet the needs of students and the school. At the same time, pay attention to the excavation and supplementation of off-campus resources, and guide more organizations and individuals, such as communities, district teaching and research offices, scientific institutes, market institutions, social organizations, and professionals. Encourage diverse subjects to give full play to their respective strengths, so as to solve the problem of resource support after school.

\section{Evaluation Indexes and Evaluation of Students' Comprehensive Litera- cy Development Based on Personalized Supplementary Education}

The comprehensive literacy evaluation of a student is like a "stethoscope". Through the evaluation, students can obtain multiple "diagnostics" such as self-examination, peer evaluation and evaluation of others. "You can break out of the limitations of your personal perspective, know all your strengths and weaknesses in real time, understand the growth and development status of your classmates around you, and stimulate your own awareness of active growth." Personalized supplementary education also needs to incorporate student comprehensive literacy evaluation into supplementary education. "Promote teaching by evaluation, promote learning by evaluation, and promote growth by evaluation." Teachers use evaluation reports to understand students' progress and deficiencies and provide targeted guidance. Students use evaluation reports to understand their development and work together to implement development goals and consolidate the road of student growth (Zhang \& Ma, 2015).

\section{Models and Characteristics of Personalized Supple- mentary Education}

Personalized supplementary learning combines static supplementary learning and dynamic supplementary learning, and divides supplementary learning model into three types: supermarket, inquiry and interactive.

\section{Supplementary Education Model}


1. Supermarket. Supermarket-style supplementary learning is to provide supplementary learning resources such as tutorial micro-lectures, tutorial courseware, analysis of important and difficult points, homework guidance, consolidation exercises, and assignment analysis of three types of supplementary courses in the resource library. To help students learn independently, remedy and improve themselves according to their actual use of resources.

2. Inquiry. Inquiry-based supplementary study is based on the problems and actual differences in classroom learning. In the case that autonomous remedy cannot be effectively achieved, students can ask their own questions, doubts, and difficulties through the platform space. Common problems are provided by the auxiliary teacher with common learning resources and learning guidance; personal problems are provided by the auxiliary teacher with personalized and precise learning guidance.

3. Interactive. Interactive supplementary learning is mainly suitable for after-school tutoring in the literacy and hobby specialty auxiliary school, including the demonstration of the completion of the phased learning tasks, the analysis and guidance of problems during the task completion process, the guidance of new tasks, and exchanges and discussions among similar students.

\section{Construction Characteristics}

\section{Compared with the Traditional Auxiliary Education}

Online and offline, convenient and auxiliary learning. The main form of teaching is collective class teaching. The goal is to meet the collective and common learning needs of students, and to pay more attention to solving the problem of "universal" students. The online personalized counseling system focuses more on solving the problem of insufficient supply of personalized demand in collective teaching, and provides students with targeted, multiple forms of supplementary and prosperous teaching supplements.

The advantage of using the network for coaching is that it avoids hidden dangers of traffic safety due to transportation, and also saves a lot of time and costs (Ventura, 2010). Using the Internet, students can consult questions from different places and with tutors in different places and learn to establish new social relationships online (Dong et al, 2014). Because of the openness of the network, students can use the information network platform to share software and hardware resources, and to obtain rich knowledge through teacher guidance. Information resources with huge amounts of information and knowledge are conducive to the development of students' innovative thinking (Liu, 2016).

Teach according to his aptitude and supplement his personality. The Internetbased personalized supplementary study combines data collection, data analysis, and data application, collects data generated during the online learning process of students, and uses big data analysis technology to analyze and clarify student learning. Personalized supplementary learning integrates online and offline student learning data and re- 
sources, making full use of these data and resources to help teachers understand the learning needs and characteristics of students, so that teachers can provide targeted after-school tutoring, and students can learn independently (Ventura \& Jang, 2010).

\section{Compared to Social Aid}

1. Public welfare. The school's personalized supplementary education adheres to the concept of "appropriate education for each child", and provides students with free after-school online tutoring through the "Internet +" personalized supplementary education. Compared with social supplementary education, the school's personalized supplementary education makes full use of the school's existing resources and platforms to achieve free supplementary education after school.

2. School-based. The construction of the school's personalized supplementary education is based on the existing conditions of the school, starting from the student's academic situation, and taking student development as the starting point, actively developing high-quality courses and brand curriculum teaching resources in the school, and integrating the life experience of teachers and students, Knowledge reserves, cultural refining, etc. are transformed into curriculum resources to achieve school-based internet platforms "for schools, based on schools, and to schools" (Lin, 2018).

3. Appropriate. The construction of the school's personalized supplementary education starts from the school's situation and follows the law of student learning and development. The purpose of the school to guide teachers to participate in the construction of personalized supplementary courses is to make the supplementary courses more suitable for the needs of students, closer to the students 'study and life, and to meet the needs of students' personality development to the greatest extent.

4. Developmental. The school's personalized supplementary learning platform is student-oriented, starting from the actual situation of the students, taking into account the needs, interests, and values of the students, respecting the differences of the students, and striving to make each child's personality public, ability cultivated, and potential tapped Let each student achieve harmonious development in autonomous learning.

\section{Measures of Personalized Supplementary Education}

\section{Establishing a Supplementary Learning Platform on the Internet}

The personalized supplementary education platform is an online after-school supplementary study room with different levels, different categories, and different needs according to the learning level of students. The overall design consists of several supplementary study rooms in three major sections: disciplinary supplementary, literacy, and 
hobby specialty. Students and parents independently determine the auxiliary school to carry out auxiliary studies through the online selection and auxiliary system according to the current learning level of the students and individual learning needs.

On the auxiliary education platform, there are several modules: live broadcast center, resource center, course center, homework center and interactive center. Students can watch the teacher's knowledge summary or homework explanation in the live broadcast center within the specified time. The personalized auxiliary education platform will also push the corresponding exercises according to the student's learning situation. Students can see the pushed personalized assignments in the homework center. After completing the online submission of the exercises, the system will automatically approve them, which can get timely feedback and detailed analysis. Teachers can check the knowledge of all students, and parents can check their children's learning progress and reports on a regular basis. Teachers and students can also communicate online through the interactive center to help answer questions.

\section{Effectively Organize Training of Teacher}

Internet online after-school supplementary studies have put forward new requirements for teachers' capabilities, such as "core responsibilities and abilities such as content coaching, metacognitive coaching, process coaching, advice and consulting, evaluation, technical support and resource production" (Denis \& Watland, 2004), so schools need to organize teacher training on a regular basis to ensure the effectiveness of online tutoring for teachers.

\section{Build a Good Education Model}

Establishing a good education model is the theoretical basis for individualized supplementary learning. The establishment of an education model requires students as the main body, and incorporates all aspects of teaching, so as to achieve through-learning before, during, and after class, so as to promote students' independent inquiry and independent learning. Organize student previews before class to allow students to enter the classroom with questions and stimulate students' desire for autonomous learning. At the same time, teachers use information technology to understand students' previews and make targeted lessons; use group learning, collaborative learning, and task learning in the classroom. It organizes student exchanges and discussions. Teachers guide students to answer questions and guide students to summarize and condense. This allows students to change from passively receiving knowledge to actively exploring and learning knowledge. Teachers are transformed from classroom leaders to classroom instructors.

Understand and Be Proficient in Using Educational Platforms, Especially Learning to Use the Web for Live Broadcasts 
Teachers are users of the personalized auxiliary learning platform. Schools need to train the lead teachers in advance to help teachers better understand the functions in the platform. In order to facilitate the use of the platform to assist students to personalize the learning of students, especially to guide teachers to learn to explain the knowledge points through the live broadcast function in the platform; meanwhile, the use of the strong interactivity of the live broadcast on the web has the advantage of enhancing communication and communication with students to meet the diverse needs of today's student learning styles.

\section{Personalized Supplementary Learning Courses}

After-school supplementary learning is an extension and supplement of teachers' teaching, and "teachers are the leading force in the construction of online courses, are the planners for the construction of the curriculum ontology, and are responsible for the effectiveness of the curriculum." (Zhang, 2014) In the middle, teachers need to be guided to develop a personalized curriculum system for supplementary studies. (1) Strengthen the connotation construction of after-school auxiliary school and the toplevel design of three types of after-school auxiliary courses; guide teachers to sort out the knowledge points of teaching, condense the content of a week's lessons into 40 minutes, and conduct important knowledge points within a week to help students outline and help them to consolidate what they have learned. (2) According to the learning situation of students, formulate a relatively complete and systematic hierarchical improvement plan, classify supplementary learning topics, and then provide targeted counseling to students to meet the different needs of student learning. (3) Form a semester system and even a school year system to form the design and arrangement of teaching and research group and lesson preparation group after-school supplementary learning.

\section{Improve Teachers' Ability to Communicate Online}

Studies have shown that "good communication between teachers and students is an important way to achieve teaching goals and achieve practical results" (Xu, 2018). Affected by the network environment, network culture often requires breaking restrictions and free expression. Students' entertainment and self-expression are highly demanding. The network provides various social and entertainment channels to meet the needs of young students. Using the network for online communication becomes it is an important channel for students' daily communication. In online chat, chat words and emoticons have become the characteristics of modern chat; especially the use of emoticons has greatly enhanced the emotional color of the chat language. Therefore, teachers should learn the skills of communicating with students online, improve their ability to communicate online, and enhance the effectiveness of teaching communication (Watson et al., 2009). At the same time, teachers should pay attention to using inspiring words when conduct- 
ing online guidance and communication, so as to promote the motivation of students' autonomous learning (Zhu, 2005).

\section{Understand the Academic Situation and Learning Needs of Students}

The auxiliary education platform sets up a space for students to ask questions. After entering the auxiliary room, students can use three methods: text input, voice input and photo upload to ask questions. After the students' doubts are raised, the teacher first sorts and sorts them manually, and screens out the most prominent and eager to solve the problems. Answers online in text, video, voice, or a combination of the three, and then sorts and counts the relevant data to get them analyzed, judged and fed back. Second, the platform will also use related technologies to automatically collect information about students' questions and queries, organize and classify them, and form statistical reports for teachers to assist in preschool analysis, judgment, and feedback.

The big data formed by the after-school supplementary learning platform is used for synchronous assistance, helping to solve students' learning difficulties and learning for help, making the after-school supplementary learning more targeted and effective. Meanwhile, the lesson preparation group improves and optimizes the subject classroom teaching based on the big data analysis report of after-school supplementary study. Students can also use the platform to form big data for autonomous learning.

\section{Carry Out Online After-School Supplementary Stud- ies}

\section{Summary and Combing of One-Week Class Knowledge}

The summary and combing of subject knowledge can help students consolidate classroom knowledge, remedy deficiencies and omissions, and optimize classroom teaching results. Personalized tutoring takes the student level as a unit, divides the taught class into three performance levels, and pulls students at different levels into different tutoring groups, so that teachers can provide after-school tutoring at different levels. The teacher summarizes and explains the knowledge points within a week, and the general lecture time is one hour.

\section{Student Online Assignment Guidance}

Homework is an integral part of teaching work. Teachers can provide necessary guidance to students with homework difficulties through a personalized auxiliary learning platform so that they can successfully complete homework and consolidate their knowledge. In this process, the teacher cooperates with the lecturer and on the premise of understanding the learning progress of the class, selects test questions from the ques- 
tion bank, and publishes the class assignment groups at different levels. When selecting assignments, you can filter the test questions by question type classification and intelligent sorting, check the assignments based on the difficulty coefficient and accuracy rate of each question, and finally assign them to the group of the corresponding level by publishing the assignment function. Therefore, teachers can guide students' work at different levels, collect student learning data through the platform, and improve classroom teaching based on the obtained data.

\section{Student Growth Guidance}

Students have individual differences, and different students have different attitudes towards the same thing. Therefore, the growth of students requires not only academic guidance, but also psychological and planning guidance. This requires teachers to provide psychological counseling based on the individual differences of different students, to help students understand themselves, to stimulate students' interest in learning, to establish a collective consciousness, to cultivate the ability to recognize and solve problems, and to form a cheerful, gregarious and independent healthy personality. Instruct students to rationally plan their own life development path. Specifically, it includes the establishment of students' life development goals, reflections on the path of selfdevelopment, and planning of life development routes (Wang, 2018).

\section{Implementation Overview and Effect}

\section{Overview of the Implementation of Online Coaching}

The online tutoring plan project entrusts relevant professional companies to build an online service platform to screen key teachers in nine disciplines including Chinese, Mathematics, English, Physics, Chemistry, Biology, History, Geography, Ethics, and the Rule of Law. At the same time, it is necessary to dig out the resources outside the school community, and pay attention to the matching and supplementation of the resources inside and outside the school. Personalized supplementary education is carried out through the school's personalized supplementary education platform every semester (excluding winter and summer vacation) from 19:00-21:00, Mondays to Fridays, Saturdays and Sundays and 8:00-22:00 on statutory holidays.

The families of students participating in supplementary study after class must have a desktop fixed terminal with Internet access conditions, parents with monitoring capabilities, and must not use smart phones. Parents must submit a written application to provide the parent's real-name system information; after the platform performs identification verification, the verification can be entered before it can be entered; students and parents $\log$ in to the online auxiliary education platform with their account passwords. 
During the tutoring process, students enter the self-selected supplementary room and communicate with the supplementary teacher according to the online supplementary study time and duration arranged by the school. The supplementary study is generally designed in two stages. The first period of time is the time for concentrated questioning and the second period of time is the concentrated (individual) question answering and the concentrated (individual) display communication. The assumption of this setting is that students can only find problems and doubts on the basis of review consolidation and autonomous work, so that the supplementary learning is more targeted and effective.

In actual operation, more than 100 teachers from schools and communities participated in online tutoring, and a total of nearly 2,000 students answered individualized learning problems in different subjects. This includes combing and explaining the key points and difficult issues of the classroom knowledge, as well as the confusion of students in autonomous learning. In the teacher-student interaction, students can also ask questions about learning interests other than textbooks, which meets the needs of students' personalized learning outside the classroom.

\section{Implementation Effect}

\section{Transformed Student Learning Styles, Enabling Students to Learn Autono- mously}

Some scholars have studied that the use of computers to assist students in learning can strengthen their awareness of learning and the self-awareness of the way they did (Craig \& Lain, 2003). Personalized supplementary education focuses on the cultivation of students 'autonomous learning ability, and uses layered counseling and autonomous learning to improve students' sense of effectiveness. Encourage students to study hard, continue to use high-level learning strategies and choose challenging learning tasks within their abilities to make students interested in learning content and experience happiness.

\section{Reduce Family Education Burden and Promote Education Equity}

Mark Bray researched the time and cost of students participating in for-profit afterschool tutoring activities in Hong Kong, and pointed out that "we must monitor the impact of after-school tutoring on the physical and mental health of students and the impact on students' family life. It is also necessary to face up to that tutoring activities may make the equality of educational opportunities empty talk" (Bray, 2013). Therefore, the free supplementary learning services provided by "Open Counseling" have met the students' tuition and learning needs to a certain extent, increasing the channels for offcampus learning, and at the same time reducing the families of students, especially those with relatively low economic income and difficulty in affording market counseling Cost pressures household financial burden (Chen et al., 2019). 


\section{Attach Importance to Student Quality Evaluation and Promote Students' All- Round Development}

Education as an activity for cultivating people is to make each person's personality fully and freely and healthily develop, so that everyone has a high degree of autonomy, independence and creativity. Personalized supplementary learning revolves around core literacy design-related learning tasks and goals, inspiring students to think about how to achieve it in a unique and personalized way. In addition, the personalized supplementary study focuses on the evaluation of student literacy. Through evaluation, students have a clearer understanding of themselves, and design personalized learning programs and paths that match the growth of students and conform to their physical and mental development laws, and seek individual knowledge. The needs and development are unified to promote the all-round development of students.

\section{Conclusions}

The "China Education Modernization 2035" document states that the integration of education and information technology is an effective way to achieve the organic combination of large-scale education and personalized training. In the face of collective teaching, education scale coverage and individualized needs have become contradictory, and personalized education via the Internet provides a way for students' personalized learning and development needs. We take the school-based practice of Middle School A in Jiangsu Province, China as an example to explain the process and method of the construction and practice of Internet-based personalized supplementary learning, with a view to providing relevant ideas for how schools can use the Internet for personalized supplementary learning. It is true that the school's existing education support system is still insufficient. In the follow-up development, after-school tutoring can improve students' sense of happiness and experience. In society, take the initiative to interact with others, transform what they have learned in the classroom into practical knowledge, actively explore and experience the external world, adapt to social life with a peaceful mindset, and increase children 's happiness experience Opportunities to ensure children's mental health “( Chen \& Lu, 2009), so as to promote the development and evolution of richer educational supplementary education and educational services that meet diverse and diverse needs. 


\section{References}

Bray, M. (1999) The shadow education system: Private tutoring and its implications for planners. Fundamentals of Educational Planning No. 61. Paris: UNESCO Intern Insti Edu Plan: 97.

Bray, M. (2013) Benefits and Tensions of Shadow Education: Comparative Perspectives on the Roles and Impact of Private Supplementary Tutoring in the Lives of Hong Kong Students. J Inter Compa Edu, 2 (1):18-30.

Brigitte, D., Philip, W., Sebastien, P., Nathalie, V. (2004) Roles and Competencies of the e-Tutor (Learn Nett project). Network Learn Confer, (4):5-7.

Chen, L., Liu, J., Yu, S.Q. (2019) Thoughts on the Key Issues in the Promotion of Personalized Online Education Public Services: Practical Reflections on the Open Online Tutoring Program for Middle School Teachers in Beijing. China Edu Tech, 11:80-90

Chen, Q.Y., Ren, S.H. (2019) Review on the Research of Supplementary Courses in Primary and Middle Schools. Teach Manag, 4:23-26

Chen, S.Y., Luo, L. (2009) After-school time use in taiwan: effects on educational achievement and well-being. Adolescence, 44: 891-909.

Craig, Z., Lain, M. (2003) Student use of computer - assisted learning (CAL) and effects on learning outcomes. Bambed, 31(2):146-150.

Dong, Y., Zhou, Y., Gao, L., Huang, R.H. (2014) Enlightenment of after-school tutoring on effective learning of students in the network age. Elec Edu Res, 5:35-58

Fan, Y.Q. (2003) On the pros and cons of part-time teachers. Edu Occu, 21.

He, K.K. (2005) Theories and methods of deep integration of information technology and curriculum. Elec Edu Res, (1):7-15.

Lin, J.D. (2018) Research on school-based internet platform in ideological and political education. Edu Rev, 7:138-141.

Liu, Y.P. (2016) Research on the effective combination strategy of classroom teach- ing and network tutoring teaching. $\mathrm{J}$ Heihe, 09 (5):147-148.

Ma, X.Q. (2010) Actively promoting the reform of the evaluation of education quality in primary and middle schools. Edu Res, 5.

Marc, B., by Yang, H.J. (2007) Education tuition and the cost of private education. Beijing: Beijing Nor Univ Press, 157.

Ventura, A., Jang, S. (2010) Private tutoring through the internet: globalization and offshoring. Asia Pacific Edu Rev, 11 (1):59-68.

Wan, S.J. (2016) Practice and strategy of personalized counseling for junior high school biology based on "Ape Question Bank". Edu Infor Tech, 5:30-32

Wang, X.F. (2018) The connotation, dilemma and transcendence of the growth tutor system. Teach Manag, 8:19-22.

Watson, J., Gemin, B., Ryan, J., Wicks, M. (2018) Keeping Pace with K-12 Online L earning: An Annual Review of State-level Policy and Practice [EB / OL]. https:

//static1.squarespace.com/ static / 59381b9a17bffc68bf625df4 / t / 5949b597f7e0abeec2b aa462 / 1498002847830 / Keeping Pace + 2009.pdf, 11-07.

Wen, Y.F., Zhu, J., Zhai, B.L., Su, X.M., Ren, S.Y. (2017) Application of network teaching in extracurricular counseling for middle school students. Chin Edu Infor, 16:86-90.

Wu, X.W. (2013) A brief analysis of the current extracurricular counselling fever for primary and middle school students. Basic Edu Res, 20.

Xinhua News Agency. (2016) "China 's extracurricular tutoring" supply of gold "exceeded RMB 800 billion in 2016", December 27 (http://www.gov.cn/shuju/2016-12/27 / content_5153561.htm)

Xu, Z.H. (2018) Thoughts on online communication between teachers and students in colleges and universities under the background of the Internet: data survey of 
sample college students based on SPSS. Quality Edu West, (07): 107-110.

Xue, H.P., Fang, C.C. (2019) Extracurricular tutoring for compulsory education in China: status quo and trends. Edu Eco Rev, 4:75-97.

Zhang, A.D. (2014) Network course construction based on school network teaching platform. Text Appar Edu, 10 (5): 431433.

Zhang, B.M., Ma, C. (2015) Nankai University: Personalized Supplementary Schoolbased Scientific Growth Director "Cheers". China Edu News, 7-16

Zhu, Y.Z. (2005) The advantages of online education and the role of tutors. Hith Voca Edu, 23:19-20.

Received: 28 September 2019

Revised: 21 October 2019

Accepted: 06 November 2019 